\title{
Arterial, arterialized venous, venous and capillary blood glucose measurements in normal man during hyperinsulinaemic euglycaemia and hypoglycaemia
}

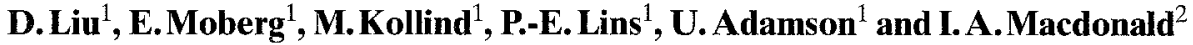 \\ ${ }^{1}$ Department of Medicine, Karolinska Institute, Danderyd Hospital, Danderyd, Sweden and \\ ${ }^{2}$ Department of Physiology and Pharmacology, University of Nottingham Medical School, Nottingham, UK
}

\begin{abstract}
Summary. The purpose of this study was to evaluate the effectiveness of the warm-air box method on the arterialization of venous blood during euglycaemia and hypoglycaemia. Six healthy male volunteers were studied using an $\mathrm{i}$. v. infusion of insulin $\left(144 \mathrm{mU} \cdot \mathrm{kg}^{-1} \cdot \mathrm{h}^{-1}\right)$. Arterial blood glucose was clamped at the baseline level for the first $30 \mathrm{~min}$ and subsequently reduced to 3.2 and to $2.5 \mathrm{mmol} / 1$ for $20 \mathrm{~min}$. At each stage, including prior to insulin infusion, arterial, arterialized venous (heating the hand in a warm-air box set to $55-60^{\circ} \mathrm{C}$ ), venous and capillary blood samples were taken simultaneously for analyses of blood glucose and oxygen saturation (not for capillary blood). The oxygen saturations in arterialized blood were approximately $3 \%$ below the arterial values. The arterial-arterialized difference of blood glucose was about $0.1 \mathrm{mmol} / 1$ (the $95 \%$ confidence interval: from -0.19 to $0.41 \mathrm{mmol} / \mathrm{l}$ ), which tended to correlate with the difference in oxygen saturations between the arterial and
\end{abstract}

arterialized blood samples $(r=0.25, p=0.08)$. During the test the forearm venous blood oxygen saturation increased by $9 \%$ and the arteriovenous difference in blood glucose ranged from 0.2 to $0.5 \mathrm{mmol} / \mathrm{l}$ which correlated significantly with the difference in oxygen saturations $(r=0.48$, $p<0.001)$. Capillary glucose was similar to the arterialized value. Rectal temperature was stable during the experiment. We conclude that the heated hand technique using the warmair box sufficiently arterializes venous blood so that the glucose measurement in the arterialized blood provides a reasonable estimate of the arterial value and that the venous blood from the contralateral forearm is also markedly arterialized, probably reflecting a vasodilator effect of heating.

Key words: Hypoglycaemia, euglycaemia, insulin, arterial, arterialized venous, venous and capillary blood glucose, blood oxygen saturation.
During hyperinsulinaemic glucose clamp studies, the arteriovenous difference in blood glucose concentration is dependent on the sensitivity of the tissue to insulin and the circulating insulin level as well as the local blood flow. In order to accurately investigate the effects of glycaemic alteration on physiological responses and on the secretion of hormones, the arterial blood glucose concentration should be monitored. However, there are considerable difficulties in obtaining arterial samples and there are also some risks associated with arterial cannulation. Many investigators have therefore measured the arterialized venous blood glucose level from a heated hand using either a warm-blanket or a hot-air box. It has recently been demonstrated, however, that the warm-blanket hand heating method may not satisfactorily arterialize venous blood [1] and that it increases the body temperature considerably and raises the deep venous blood oxygen content in the contralateral forearm [2]. The alternative procedure of heating the hand by a warm-air box has been reported not to affect the body temperature and to have a minimal effect on the cardiovas- cular system [3]. However, the degree of arterialization achieved with this method during hyperinsulinaemia has not been fully examined. During hypoglycaemia, quite a small difference in arterial blood glucose might be of critical importance when the blood glucose level is close to the glucose threshold of the counterregulatory process [4]. The purpose of this study was, therefore, to evaluate the warmair box method on the effectiveness of blood arterialization during hyperinsulinaemic euglycaemia and hypoglycaemia in healthy subjects. The arterial, arterialized venous and venous blood oxygen saturation was assessed and glucose concentrations were also measured in these samples as well as from capillary blood.

\section{Subjects and methods}

Six healthy male volunteers aged $31 \pm 3$ years (mean \pm SD) (body mass index $24.2 \pm 2.4 \mathrm{~kg} / \mathrm{m}^{2}$ ) participated in the study. None was taking any medication. Informed consent to participate in the study was 


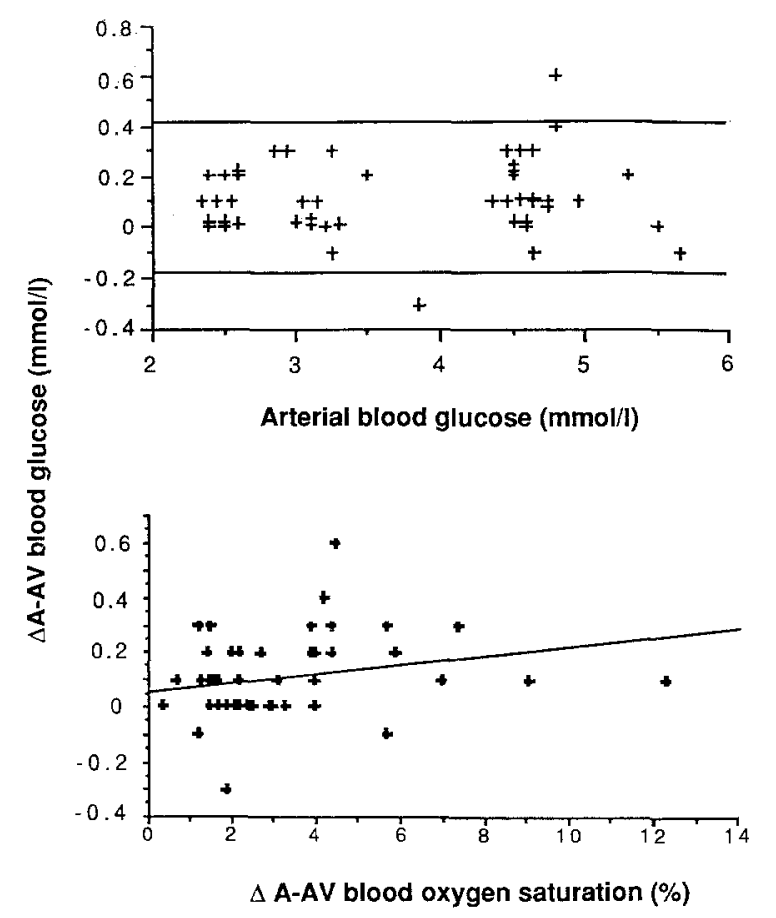

Fig.1. The relationships between the arterial-arterialized difference of blood glucose ( $\triangle \mathrm{A}-\mathrm{AV}$ blood glucose) and arterial blood glucose, and arterial-arterialized difference of blood oxygen saturation ( $\triangle$ A-AV blood oxygen saturation) ( $n=48, r=0.25, p=0.08)$, during hyperinsulinaemic euglycaemia-hypoglycaemia clamp experiments in six healthy subjects. The two horizontal lines in the upper part of the figure indicate the $95 \%$ confidence interval

obtained from all of the subjects, and the study was approved by the local ethical committee. The experiments took place at a room temperature of $24^{\circ} \mathrm{C}$. On the morning of the test, after an overnight fast, the subjects rested in a comfortable, semi-recumbent position for $30 \mathrm{~min}$ prior to the experiments. Under local anaesthesia, a short teflon cannula was inserted into an antecubital vein of each arm, for infusions (right arm) and for venous blood sampling (left arm). A cannula was placed in a dorsal hand vein on the right hand which was placed in a warm-air box (Department of Medical Physics, Queen's Medical Centre, Nottingham, UK) heated to $55-60^{\circ} \mathrm{C}$ to arterialize the venous blood samples and another cannula was inserted into the radial artery on the left hand for arterial blood sampling. The cannulae were kept patent with $150 \mathrm{mmol} / \mathrm{l} \mathrm{NaCl}$. The experiment was divided into four stages. Before the insulin infusion was started, the subject had a 30-min rest and blood samples were taken (stage 1). Next, insulin (Actrapid Human, Novo A/S, Copenhagen, Denmark) was intravenously infused using a pump (Imed volumetric infusion pump, Milton Trading Estate, Oxon, UK) at a rate of $144 \mathrm{mU} \cdot \mathrm{kg}^{-1}$. $\mathrm{h}^{-1}$ and the arterial blood glucose was clamped by a variable $\mathrm{i}$. v. infusion of glucose $(20 \%)$ adjusted according to the arterial blood glucose level measured at $1.5-5 \mathrm{~min}$ intervals. During insulin infusion, arterial blood glucose was maintained at the baseline level during the first 20-30 $\mathrm{min}$ (stage 2). It was then reduced to $3.2 \mathrm{mmol} / \mathrm{l}$ over approximately 10-15 min and maintained for 20-30 min (stage 3), after which it was further decreased to $2.5 \mathrm{mmol} / \mathrm{l}$ and maintained there for 20-30 min (stage 4). At each stage, there were two sampling times, 15-25 min apart, during which arterial, arterialized venous, venous and capillary blood samples were taken simultaneously for analyses of blood glucose and oxygen saturation (not for capillary blood). Blood glucose was immediately determined by two glucose analyzers (Yellow Springs Instruments, Yellow Springs, Ohio, USA) in random order. The intra- and inter-day coefficient variations $(\mathrm{CV})$ of the glucose measurement were $1.4 \%$ and $2.3 \%$, respectively. Blood oxygen saturation was measured (ABL3, Radiometer, Copenhagen, Denmark) within 20 min. Rectal temperature was measured before and at the end of the experiment.

\section{Statistical analysis}

The average values of two measurements of variables in each stage were calculated. Statistical analysis was made with one- or two-way analysis of variance (ANOVA), paired $t$-tests and the Pearson coefficient of correlation (in which every individual measurement was included). Unless otherwise stated, the data are expressed as means \pm SEM.

\section{Results}

The actual arterial blood glucose levels achieved during the clamp stages were very close to the target levels and the inter-individual variations of arterial blood glucose concentration were low (Table 1). The intra-individual variations (CV) of arterial blood glucose levels ranged from 1.2 to $7.7 \%$. There was no significant difference be-

Table 1. Arterial (A), arterialized venous (AV), venous (V) and capillary (C) blood glucose and oxygen saturation values (means \pm SEM) during hyperinsulinaemic euglycaemia-hypoglycaemia clamp experiments in six healthy subjects

\begin{tabular}{|c|c|c|c|c|}
\hline & \multirow{2}{*}{\multicolumn{4}{|c|}{$\begin{array}{l}\text { Oxygen saturation }(\%) \\
\text { Blood glucose }(\mathrm{mmol} / \mathrm{l})\end{array}$}} \\
\hline & & & & \\
\hline & $\mathrm{A}$ & AV & $\mathrm{V}$ & $\mathrm{C}$ \\
\hline euglycaemia (stage 1) & $4.78 \pm 0.16$ & $4.70 \pm 0.19$ & $4.52 \pm 0.19^{\mathrm{a}}$ & $4.68 \pm 0.20$ \\
\hline $\begin{array}{l}\text { Hyperinsulinaemia } \\
++\end{array}$ & $97.6 \pm 0.20$ & $95.0 \pm 0.51^{\mathrm{c}}$ & $80.8 \pm 2.68^{d}$ & \\
\hline euglycaemia (stage 2) & $4.73 \pm 0.13$ & $4.55 \pm 0.09$ & $4.28 \pm 0.10^{\mathrm{b}}$ & $4.55 \pm 0.15^{\mathrm{a}}$ \\
\hline $\begin{array}{l}\text { Hyperinsulinaemia } \\
+\end{array}$ & $97.8 \pm 0.07$ & $94.8 \pm 0.71^{b}$ & $82.1 \pm 1.21^{\mathrm{d}}$ & \\
\hline mild hypoglycaemia (stage 3 ) & $3.19 \pm 0.04$ & $3.09 \pm 0.07$ & $2.93 \pm 0.05^{\mathrm{c}}$ & $3.14 \pm 0.04$ \\
\hline $\begin{array}{l}\text { Hyperinsulinaemia } \\
\quad+\end{array}$ & $98.1 \pm 0.20$ & $93.8 \pm 1.47^{\mathrm{a}}$ & $89.7 \pm 1.29^{\mathrm{d}}$ & \\
\hline
\end{tabular}

${ }^{\mathrm{a}} p<0.05,{ }^{\mathrm{b}} p<0.01,{ }^{\mathrm{c}} p<0.005,{ }^{\mathrm{d}} p<0.001$, as compared with the arterial values 
tween the two blood glucose levels measured at each stage of the clamp experiment. The rectal temperature was stable during the experiment $\left(37.0 \pm 0.09\right.$ vs $36.9 \pm 0.11^{\circ} \mathrm{C}$, NS).

The arterialization technique generated oxygen saturations in arterialized venous blood which were approximately $3 \%$ below the arterial values (Table 1 ). In consistency with this, there was a small difference between the arterial and the arterialized venous glucose levels which was about $0.1 \mathrm{mmol} / 1$ (Fig. 1). The 95\% confidence interval of the difference ranged from -0.19 to $0.41 \mathrm{mmol} / 1$ (means $\pm 2 \mathrm{SD}$ ). This difference in blood glucose was similar before and during insulin infusion, but tended to be smaller at the lower blood glucose levels. The difference of blood glucose between the arterial and arterialized venous blood tended to correlate with the difference of blood oxygen saturations between these two compartments $(r=0.25, p=0.08)$ (Fig. 1$)$.

The differences in arterial and forearm venous blood glucose levels ranged from 0.2 to $0.5 \mathrm{mmol} / 1$ (Table 1 ). The largest difference appeared at stage 2, i.e. during hyperinsulinaemic euglycaemia; thereafter it decreased slightly as the experiment continued. During this period the forearm venous blood oxygen saturation increased by $9 \%$. The arteriovenous difference in blood glucose correlated significantly with the arteriovenous difference in blood oxygen saturation $(r=0.48, p<0.001)$.

The capillary blood glucose concentrations were similar to the arterialized venous values. During hypoglycaemia, capillary glucose was slightly higher than the arterialized venous glucose levels and was closer to the arterial glucose values (Table 1).

\section{Discussion}

This study demonstrates that the arterialization technique used here, i.e. the warm-air box $\left(55-60^{\circ} \mathrm{C}\right)$, can sufficiently arterialize venous blood and achieve an arterialized blood glucose level close to the true arterial value. The fact that the differences in the arterial and arterialized blood glucose tended to correlate with the differences in the arterial and arterialized blood oxygen content again suggests that the accuracy of arterialized blood glucose measurement as reflecting the arterial values is dependent on the degree of arterialization of blood oxygen saturation. This study also confirms that the warm-air box technique does not influence body temperature.

The arteriovenous difference of blood glucose in this study was smaller than that recorded in a previous study from our laboratory in which the same insulin infusion was given while arterial and forearm venous blood samples were taken without hand heating [4]. This difference may be explained by an arterialization effect of the venous blood in the contralateral forearm since venous blood oxygen saturation increased by $9 \%$ during the present experiment. The significant correlation between the arteriovenous differences of blood glucose and blood oxygen content indicates such an arterialization effect, which may be due mainly to the vasodilating effect on the forearm superficial vasculature when heating the contralateral hand $[1-3,5]$.
During insulin-induced hypoglycaemia, the arteriovenous difference in blood glucose is influenced by plasma insulin concentrations, counterregulatory factors and ambient blood glucose levels [4]. In the present study, the difference between the arterial and the arterialized venous blood glucose levels was so small that the dependency of this difference on insulin and glucose levels could not be assessed. Thus, under such conditions, arterialized blood glucose values provide a reasonable estimate of the arterial glucose levels, and are unlikely to introduce major errors in the interpretation of studies. However, in the present study there was a small difference in the arterial and the arterialized blood glucose levels which was consistent and reached statistical significance during stage 4 (in marked hypoglycaemia) and the blood oxygen saturation was also significantly lower in the arterialized venous blood compared to the arterial blood. Thus, the arterialization process is not $100 \%$ effective but it is unlikely that an error of $0.1 \mathrm{mmol} / \mathrm{l}$ in the estimation of arterial blood glucose would be of major importance since it represents the resolution and accuracy of most methods for measuring blood glucose.

This study was not designed to evaluate the effect of plasma insulin on the difference of arterial-arterialized glucose over as large a range of concentrations as applied by other investigators $[6,7]$. The largest discrepancies in arterial and arterialized venous glucose were noted with the first samples taken during stages 2 and 3 , with better agreement for the second samples at each stage. As these first samples were only taken 5-10 min after achieving each glucose level, it is unlikely that a true steady state had been achieved. Thus, the disagreement between the arterial and arterialized venous samples may be partly due to this nonsteady state producing errors when sampling times are simultaneous. This explanation is supported by the fact that one of the samples taken at the start of stage 3 actually had an arterialized value higher than the arterial. However, once a more steady state was achieved the disagreement between the arterial and arterialized glucose levels was within $0.2 \mathrm{mmol} / 1$, and was even less in hypoglycaemia.

In summary, this study demonstrated that the heated hand technique using the warm-air box sufficiently arterializes venous blood so that the glucose measurement in the arterialized blood provides a reasonable estimate of the arterial values and that the venous blood from the contralateral forearm is also markedly arterialized, probably reflecting a vasodilator effect of heating.

Acknowledgements. We acknowledge the excellent help of Ms R.Lidbom-Hedin. This work was supported by grants from NOVO A/S, Denmark, the Swedish Society of Medicine, the Bert von Kantzow Foundation, the Karolinska Institute, the Swedish Medical Research Council (Grant No.19x-6589) and the British Council.

\section{References}

1. Astrup A, Simonsen L, Bülow J, Christensen NJ (1988) Measurement of forearm oxygen consumption: role of heating the contralateral hand. Am J Physiol 255 (Endocrinol Metab 18): E572$\mathrm{E} 578$ 
2. Krarup T, Nurnberg B, Mikkelsen Ket al. (1990) How arterialized is blood sampled from a superficial hand vein? Diabetes 39 [Suppl 1]: $88 \mathrm{~A}$

3. Gallen IW, Macdonald IA (1990) Effect of two methods of hand heating on body temperature, forearm blood flow, and deep venous oxygen saturation. Am J Physiol 259 (Endocrinol Metab 22): E639-E643

4. Liu D, Moberg E, Kollind M, Lins PE, Adamson U (in press) A high concentration of circulating insulin suppresses the glucagon response to hypoglycaemia in normal man. J Clin Endocrinol Metab

5. Abramson DI, Tuck S, Chu LSW, Lee SW, Gibbons C, Richardson $G$ (1965) Indirect vasodilation in thermotherapy. Arch Phys Med Rehab 46: 412-420

6. Diamond MP, Hallarman L, Zych Ket al. (1990) Insulin per se suppresses counterregulatory hormone responses to hypoglycemia. Diabetes 39 [Suppl 1]: 4A
7. Bolli G, Feo PD, Perriello G et al. (1984) Mechanisms of glucagon secretion during insulin-induced hypoglycemia in man: Role of the beta cell and arterial hyperinsulinaemia. J Clin Invest 73: $917-$ 922

Received: 19 September 1991

and in revised form: 29 October 1991

\section{Dr. D. Liu}

Department of Medicine

Karolinska Institute

Danderyd Hospital

S-18288 Danderyd

Sweden 